\title{
Impact of nucleic acid self-alignment in a strong magnetic field on the interpretation of indirect spin-spin interactions
}

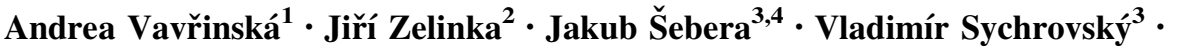 \\ Radovan Fiala $^{5} \cdot$ Rolf Boelens $^{1} \cdot$ Vladimír Sklenáŕ $^{5} \cdot$ Lukáš Trantírek $^{5}$
}

Received: 21 September 2015/ Accepted: 6 December 2015/Published online: 19 December 2015

(c) The Author(s) 2015. This article is published with open access at Springerlink.com

\begin{abstract}
Heteronuclear and homonuclear direct (D) and indirect $(\mathrm{J})$ spin-spin interactions are important sources of structural information about nucleic acids (NAs). The Hamiltonians for the D and $\mathbf{J}$ interactions have the same functional form; thus, the experimentally measured apparent spin-spin coupling constant corresponds to a sum of $\mathrm{J}$ and D. In biomolecular NMR studies, it is commonly presumed that the dipolar contributions to Js are effectively canceled due to random molecular tumbling. However, in strong magnetic fields, such as those employed for NMR analysis, the tumbling of NA fragments is anisotropic because the inherent magnetic susceptibility of NAs causes an interaction with the external magnetic field. This motional anisotropy is responsible for non-zero D contributions to Js. Here, we calculated the field-induced D contributions to 33 structurally relevant scalar coupling
\end{abstract}

Electronic supplementary material The online version of this article (doi:10.1007/s10858-015-0005-x) contains supplementary material, which is available to authorized users.

Lukáš Trantírek

lukas.trantirek@ceitec.muni.cz

1 Bijvoet Center for Biomolecular Research, Utrecht University, Padualaan 8, $3584 \mathrm{CH}$ Utrecht, The Netherlands

2 Faculty of Science, Masaryk University, Kotlářská 2, 61137 Brno, Czech Republic

3 Institute of Organic Chemistry and Biochemistry, Academy of Sciences of the Czech Republic, v.v.i., Flemingovo náměstí 542/2, 16610 Praha 6, Czech Republic

4 Institute of Physics, Academy of Sciences of the Czech Republic, v.v.i, Na Slovance 2, 18221 Prague 8, Czech Republic

5 Central European Institute of Technology, Masaryk University, Kamenice 753/5, 62500 Brno, Czech Republic constants as a function of magnetic field strength, temperature and NA fragment size. We identified two classes of Js, namely ${ }^{1} \mathrm{~J}_{\mathrm{CH}}$ and ${ }^{3} \mathrm{~J}_{\mathrm{HH}}$ couplings, whose quantitative interpretation is notably biased by NA motional anisotropy. For these couplings, the magnetic field-induced dipolar contributions were found to exceed the typical experimental error in J-coupling determinations by a factor of two or more and to produce considerable over- or underestimations of the $\mathrm{J}$ coupling-related torsion angles, especially at magnetic field strengths $>12 \mathrm{~T}$ and for NA fragments longer than $12 \mathrm{bp}$. We show that if the non-zero D contributions to $\mathrm{J}$ are not properly accounted for, they might cause structural artifacts/bias in NA studies that use solution NMR spectroscopy.

Keywords Nucleic acid · Self-alignment $\cdot$ Magnetic susceptibility - Scalar coupling · Dipolar coupling · Karplus equation

\section{Introduction}

The major sources of structural information from NMR measurements of biomolecules in isotropic solution are nuclear Overhauser enhancements (NOEs), which provide information about short $(<5 \AA)$ inter-proton distances, and indirect spin-spin interactions that are characterized by scalar coupling constants $(\mathrm{J})$, which provide information about torsion angles (Roberts 1993; Wijmenga and van Buuren 1998). In addition to these two sources, direct spinspin interactions (D), known as (residual) dipolar couplings (RDCs), reveal the relative orientations of inter-nuclear vectors with respect to the direction of the external magnetic field. The direct spin-spin interactions can be measured under conditions where the studied molecules are at 
least partially aligned with respect to the magnetic field. The alignment typically requires supplementation of NMR buffers with some type of alignment media, such as bicelles, nonionic polymers, Pf1 bacteriophages, anisotropically compressed gels or covalent modifications of investigated molecules with paramagnetic tags (Bax and Tjandra 1997; Clore et al. 1998; Rückert and Otting 2000; Sass et al. 2000; Su et al. 2008; Tjandra and Bax 1997; Tycko et al. 2000; Wöhnert et al. 2003; Zweckstetter and Bax 2001).

For proteins, NMR structure determination is predominantly based on inter-proton NOEs. However, the structure determination of nucleic acids, particularly axially symmetric and elongated NA constructs, strongly depends on the use of direct and indirect spin-spin interactions due to the inherently low proton density and the absence of longrange contacts (Zhou et al. 1999).

In contrast to both NOEs and residual dipolar couplings, for which analytical relationships between the respective observable and geometry exist, the interpretation of scalar couplings typically relies on the quantitative relationship between the local geometry and the corresponding scalar coupling, established by means of (empirical) parameterization, i.e., by measurement of Js or calculation of Js using methods of quantum chemistry on a set of model molecules with known geometry. At present, approximately 33 distinct scalar coupling constants can be employed for the conformational analysis of nucleic acids. Specifically, the ${ }^{3} \mathrm{~J}_{\mathrm{H}^{\prime} \mathrm{H} 2^{\prime}}, \quad{ }^{3} \mathrm{~J}_{\mathrm{H} 1^{\prime} \mathrm{H} 2^{\prime \prime}}, \quad{ }^{3} \mathrm{~J}_{\mathrm{H}^{\prime} \mathrm{H} 3^{\prime}}, \quad{ }^{3} \mathrm{~J}_{\mathrm{H} 2^{\prime \prime} \mathrm{H} 3^{\prime}}, \quad{ }^{3} \mathrm{~J}_{\mathrm{H}^{\prime} \mathrm{H}^{\prime}}, \quad{ }^{3} \mathrm{~J}_{\mathrm{H} 1^{\prime} \mathrm{C} 3^{\prime}}$, ${ }^{3} \mathrm{~J}_{\mathrm{H}^{\prime} \mathrm{C} 2^{\prime}},{ }^{3} \mathrm{~J}_{\mathrm{H}^{\prime} \mathrm{C}^{\prime}},{ }^{3} \mathrm{~J}_{\mathrm{H} 2^{\prime} \mathrm{C} 4^{\prime}},{ }^{2} \mathrm{~J}_{\mathrm{H}^{\prime} \mathrm{C} 1^{\prime}},{ }^{2} \mathrm{~J}_{\mathrm{H}^{\prime} \mathrm{C} 2^{\prime}},{ }^{2} \mathrm{~J}_{\mathrm{H} 2^{\prime} \mathrm{C} 3^{\prime},},{ }^{2} \mathrm{~J}_{\mathrm{H}^{\prime} \mathrm{C} 4^{\prime}}$, ${ }^{1} \mathrm{~J}_{\mathrm{H}^{\prime} \mathrm{C}^{\prime}}$, and ${ }^{1} \mathrm{~J}_{\mathrm{H}^{\prime} \mathrm{C}^{\prime}}$ couplings and their combinations are well established as good indicators of sugar conformations (Wijmenga and van Buuren 1998). Heteronuclear one-bond $\left({ }^{1} \mathrm{~J}_{\mathrm{Cl}^{\prime} \mathrm{H}^{\prime}}\right)$ and three-bond scalar couplings, namely, ${ }^{3} \mathrm{~J}_{\mathrm{H} 1^{\prime} \mathrm{C} 2 /}$ $\mathrm{C} 4$ and ${ }^{3} \mathrm{~J}_{\mathrm{H} 1^{\prime} \mathrm{C} 6 / \mathrm{C} 8}$, allow for the determination of the relative orientation of the base with respect to the sugar moiety via a description of the glycosidic torsion angle $\chi$ (Fonville et al. 2012; Ippel et al. 1996; Munzarova and Sklenar 2003; Trantirek et al. 2002). The use of scalar couplings is particularly important for the characterization of the phosphate backbone of NA, where the quantitative relations are established between the following: ${ }^{3} \mathrm{~J}_{\mathrm{C} 4^{\prime} \mathrm{P}},{ }^{3} \mathrm{~J}_{\mathrm{H} 5} \mathrm{P},{ }^{3} \mathrm{~J}_{\mathrm{H} 5} 5^{\prime} \mathrm{P}$,

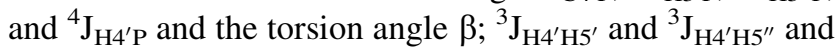
the torsion angle $\gamma$; and ${ }^{3} \mathrm{~J}_{\mathrm{H} 3^{\prime} \mathrm{P}},{ }^{3} \mathrm{~J}_{\mathrm{C} 2^{\prime} \mathrm{P}^{\prime}}$, and ${ }^{3} \mathrm{~J}_{\mathrm{C} 4^{\prime} \mathrm{P}}$ and the torsion angle $\varepsilon$ (Roberts 1993; Wijmenga and van Buuren 1998). In addition to their quantitative interpretation in terms of the local structure, the scalar couplings can be used to identify the long-range structural features of nucleic acids. Non-zero values of the ${ }^{1 \mathrm{~h}} \mathrm{~J}_{\mathrm{NH}}$ and ${ }^{2 \mathrm{~h}} \mathrm{~J}_{\mathrm{NN}}$ scalar couplings can be used as direct experimental evidence of a hydrogen bond and as a reporter of the basepairing pattern (Alkorta et al. 2008). Similarly, non-zero values of ${ }^{3} J_{\mathrm{PC}}$ and ${ }^{2} \mathrm{~J}_{\mathrm{PH}}$ across the $\mathrm{P}-\mathrm{O} \cdots \mathrm{H}-\mathrm{C}$ link report on the presence of specific structural features of nucleic acids, such as the turn-kink motif (Sychrovský et al. 2006).

Experimentally, $\mathrm{J}$ couplings are usually measured from E.COSY-type spectra (Griesinger et al. 1985), from spinstate selective (Meissner et al. 1997a; b), IPAP (Ottiger et al. 1998), quantitative J-correlation experiments (Bax et al. 1994), or from the difference in the peak positions in TROSY and decoupled HSQC spectra (Kontaxis et al. 2000). The Hamiltonians for both the indirect (J) and direct (D) spin-spin interaction have the same functional form

$H=2 \pi A_{I S} I_{Z} S_{Z}$

where $A_{I S}$ is either the scalar coupling constant $J_{I S}$ and/or the dipolar coupling constant $D_{I S}$. As a consequence, the apparent scalar coupling constant that is observed experimentally in the case of molecular alignment is $J_{I S}+D_{I S}$. Therefore, equating the measured values to $\mathrm{J}$ couplings is generally incorrect and leads to incorrect structural restraints unless the dipolar contribution is negligible. For diamagnetic proteins, random molecular tumbling effectively cancels the dipolar contributions. However, for nucleic acids, the dipolar contributions arising from the anisotropy of molecular tumbling might be significant because the inherent magnetic susceptibility of NAs causes an interaction with the external magnetic field. This motional anisotropy, the so-called self-alignment, was first mentioned as far back as by Robinson (1961), who showed that nucleic acids in solutions above a certain critical concentration can spontaneously undergo transitions from isotropic liquid to nematic liquid crystalline phases ( $>50 \mathrm{mg} / \mathrm{mL}$ for short DNA fragments) (lizuka 1978; Iizuka and Kondo 1979; Iizuka and Yang 1977; Senechal et al. 1980; Trohalaki et al. 1984). Years later, numerous experimental studies (Brandes and Kearns 1986; Rill 1986; Rill et al. 1983) investigating the effect of increasing DNA concentrations (up to $300 \mathrm{mg} / \mathrm{mL}$ ) and fragment lengths (147, 234, and $437 \mathrm{bp})$ on NMR spectral intensities confirmed this finding. In conventional applications of solution NMR spectroscopy for nucleic acid structure determination, which used short NA fragments (10-25 bp), concentration ranges of $0.5-3 \mathrm{mM}$, and the magnetic field strengths available at that time (5-14 T), the NA selfalignment was considered negligible.

Nevertheless, the interest in the self-alignment phenomenon was renewed with the availability of NMR spectrometers operating at high-magnetic field strengths, which provided sensitivity and resolution amiable to longer NA fragments (up to $40 \mathrm{bp}$ ). Between 2001 and 2004, several groups independently demonstrated that the magnetic susceptibility of nucleic acids is capable of producing sufficient self-alignment in dilute solutions of oligonucleotides of moderate lengths to measure the magnetic field-induced RDCs (fiRDCs) that can be employed for NA 
structural analysis (Al-Hashimi et al. 2001a, c; Bryce et al. 2004; Kung et al. 1995; van Buuren et al. 2004; Zhang et al. 2003). These works provided an important proof-ofconcept and showed that RDCs can be obtained under conditions that do not perturb the studied system by the use of either additives (alignment media) or NA fragment paramagnetic tagging. However, the magnitudes of the RDCs obtained from the self-alignment were several times smaller than those routinely achievable using standard alignment media. The considerable relative errors in measuring small fiRDCs have a negative influence on the quality of NA structure refinement. This limitation and the fact that the determination of the fiRDC requires measurements at least two different magnetic field strengths are the primary reasons why NA self-alignment is not routinely used to characterize nucleic acid structure.

In the past, all studies have focused on the potential of NA self-alignment to measure fiRDCs in a non-invasive manner, and the self-alignment phenomenon has not been studied in detail with respect to the interpretation of scalar couplings. The direct (D) and indirect (J) spin-spin interactions have the same form of Hamiltonian, making them inseparable within a single NMR experiment; thus, the scalar coupled spectra should always be treated as spectra "contaminated" by the dipolar contributions. In some cases, this contamination can severely taint the structure determination process. The aim of this paper is to draw attention to the consequences of NA self-alignment on the interpretation of indirect spin-spin interactions in terms of NA structure and to identify problematic situations where the self-alignment might result in structural artifacts.

\section{Materials and methods}

\section{Quantum chemical calculations}

DFT calculations of magnetic susceptibilities were performed on each nucleic acid base (A, G, C, T, and U) using the B3LYP Exchange Correlation Functional (Becke 1993) as implemented in Gaussian 09, Revision A.02 (Frisch et al. 2009). The starting geometries of the five aforementioned nitrogenous bases correspond to idealized geometries of NA bases (Clowney et al. 1996). Subsequently added hydrogen atoms were optimized at the B3LYP/6-31G** level of theory and included the implicit solvent (CPCM) described within the polarizable continuum model (Miertuš et al. 1981; Miertus and Tomasi 1982). The ensuing GIAO calculations (Cheeseman et al. 1996; Wollinski et al. 1990) of the base $\chi$ magnetic sus- ceptibility tensors were performed using the Pople triplezeta-valence basis set $6-311++\mathrm{G}(3 \mathrm{df}, 3 \mathrm{pd})$, with multiple polarizations used on all atoms (Ditchfield et al. 1971). The resulting computed nucleobase magnetic susceptibility tensors were expressed in the form of $3 \times 3$ symmetric matrix that is the sum of an isotropic (zeroth rank) and an anisotropic symmetrical (second rank) tensor.

\section{Molecular anisotropy of magnetic susceptibility}

Three-dimensional Cartesian coordinate models (NA fragments consisting of 12,24 , and $36 \mathrm{bp}$ ) were generated for the canonical conformation of the double-helical ARNA and B-DNA using the 3DNA (Lu 2003) and AMBER 10 Molecular Dynamics Software Package (Case et al. 2008). The sequences of individual fragments are listed in Table S1. The respective molecular magnetic susceptibilities of the model molecules were then calculated from tensor summations of the individual values of the nucleobase-specific magnetic susceptibilities (Bryce et al. 2004). Through an appropriate orthogonal transformation that diagonalizes the molecular magnetic susceptibility tensor into the principal axis frame and through the subsequent subtraction of the isotropic contribution, the anisotropic part of the molecular magnetic susceptibility (AMMS) tensor was obtained. The molecular tensor was described using its three non-degenerate eigenvalues and eigenvectors. The eigenvalues were sorted according to their absolute values as:

$\left|\chi_{33}-{ }_{i s o}\right| \geq\left|\chi_{11}-\chi_{i s o}\right| \geq\left|\chi_{22}-\chi_{i s o}\right|$

to determine the anisotropy $\Delta \chi$ and rhombicity $R$ of the AMMS tensor.

$\Delta \chi=\chi_{33}-\frac{1}{2}\left(\chi_{11}+\chi_{22}\right)$

$R=\left(\chi_{22}-\chi_{11}\right) / \Delta \chi$

The fiRDCs were calculated as a function of the AMMS tensor according to the following equation:

$$
\begin{aligned}
f i R D C(H z)=- & {\left[\frac{\mu_{0}\left(B_{0}\right)^{2} \Delta \chi S \gamma_{I} \gamma_{S} h}{240 \pi^{3} k T r_{I S}^{3}}\right] } \\
& {\left[\left(3 \cos ^{2} \theta-1\right) \frac{3}{2} R \sin ^{2} \theta \cos 2 \phi\right] }
\end{aligned}
$$

where $S$ is the generalized order parameter, $\gamma_{I}, \gamma_{S}$ are the magnetogyric ratios of nuclei $I$ and $S$, respectively, and $\Delta \chi$ and $R$ are the anisotropy and rhombicity, respectively, of the AMMS tensor. $r_{I S}$ is the internuclear distance, and $\theta$ and $\phi$ are polar coordinates describing the orientation of the internuclear I-S vector in the principal axis system of the molecular magnetic susceptibility tensor. 
Note Experimental validation of the reconstruction approach based on nucleobase-specific magnetic susceptibilities can be found in Bryce et al. (2004).

\section{Results and discussion}

Unlike the RDCs induced by orienting media that are evaluated by comparing the spectra measured in isotropic and orienting solutions, the magnetic field-induced dipolar couplings can never be completely switched off. If not taken into account, the fiRDCs might become a source of systematic errors. To identify the scalar couplings whose quantitative interpretation is potentially biased by NA selfalignment we simulated the magnetic field-induced dipolar contributions to all currently used J-coupling constants for NA structural analysis as a function of the strength of the external magnetic field $(9.4,11.8,22.3$, and $28.1 \mathrm{~T})$, the temperature $(278,293$, and $308 \mathrm{~K})$, and the length of the NA fragment $(12,24$, and $36 \mathrm{bp}$ ) for the two most common nucleic acid motifs, namely A-DNA (A-RNA) and B-DNA. For 15 of 33 calculated Js, the magnetic fieldinduced RDC contributions were found to exceed the typical experimental error in J-coupling determinations by a factor of two or more (Tjandra et al. 1996; Wang and Bax 1996; Yao et al. 2009). These J couplings are potential sources of interpretational bias, and they can be formally divided into two different categories: (1) ${ }^{1} \mathrm{~J}_{\mathrm{CH}}$ and (2) ${ }^{3} \mathrm{~J}_{\mathrm{HH}}$. The effect of self-alignment on the quantitative interpretation of these $\mathbf{J}$ couplings in terms of structure was analyzed in detail (vide infra). For a complete overview of the simulated RDC contributions, see Supplementary Information-Tables S2 and S3.

\section{Effect of self-alignment on the interpretation of ${ }^{1} \mathbf{J}_{\mathrm{CH}}$}

The magnitude of magnetic field-induced residual dipolar couplings is inversely proportional $\left(\mathrm{r}^{-3}\right)$ to the distance of interacting nuclei; thus, it is not surprising that one-bond ${ }^{1} \mathrm{~J}_{\mathrm{CH}}$ couplings display some of the largest magnetic fieldinduced dipolar contributions (Supplementary Information-Tables S2 and S3). Figure 1 shows the result of the simulation of the dipolar contribution to the structurally important ${ }^{1} \mathrm{~J}_{\mathrm{Cl}^{\prime} \mathrm{H} 1^{\prime}}$, which provides information about the conformation of the glycosidic torsion angle $(\chi)$; this angle describes the relative orientations of NA bases and sugar moieties in the model B-DNA fragment. The simulation was performed as a function of temperature, magnetic field strength, and length of the investigated NA fragment.

As shown in Fig. 1, the contribution of $\mathrm{fi}^{1} \mathrm{D}_{\mathrm{C1}^{\prime} \mathrm{H} 1^{\prime}}$ to the apparent ${ }^{1} \mathrm{~J}_{\mathrm{C}^{\prime} \mathrm{H} 1^{\prime}}$ primarily depends on the magnetic field strength and length of the nucleic acid fragment, whereas the temperature dependence has a marginal effect $(<10 \%$ within the range from 5 to $35^{\circ} \mathrm{C}$ ). Our calculations show that for the small model B-DNA fragment (12 bp length) and at the low magnetic field strength of $11.8 \mathrm{~T}$, the $\mathrm{f}^{1-}$ $\mathrm{D}_{\mathrm{C} 1^{\prime} \mathrm{H} 1^{\prime}}$ contribution to the apparent ${ }^{1} \mathrm{~J}_{\mathrm{C} 1^{\prime} \mathrm{H} 1^{\prime}}$ for the residue G10 reaches $-0.7 \mathrm{~Hz}$. As shown in Fig. 2, if not properly accounted for during the interpretation of the apparent ${ }^{1} \mathrm{~J}_{\mathrm{C} 1^{\prime} \mathrm{H} 1^{\prime}}$, even this relatively small contribution will lead to an approximately $28^{\circ}$ overestimation of the $\chi$ torsion angle from the established Karplus equation. However, in this case, the corresponding structural error is still within the typical error bounds for the torsion angle restraints derived from the Karplus equation $\left( \pm 30^{\circ}\right)$. Importantly, such a small fiRDC contribution does not alter the qualitative interpretation of the $\chi$ torsion angle, which is correctly assigned to the anti conformation. However, for the samesized fragment at $\mathrm{B}_{0}=22.3 \mathrm{~T}$, the corresponding $\mathrm{fi}^{1} \mathrm{D}_{\mathrm{C1}^{\prime} \text { - }}$ $\mathrm{H}^{\prime}$ contribution reaches $-2.5 \mathrm{~Hz}$ (Fig. 1; Supplementary Information-Table S2). In this case, the appropriate Karplus equation will incorrectly assign the $\chi$ torsion angle to the region between the anti and syn conformations. For a moderate sized NA fragment that is $24 \mathrm{bp}$ long at $\mathrm{B}_{0}=22.3 \mathrm{~T}$, the $\mathrm{fi}^{1} \mathrm{D}_{\mathrm{C} 1^{\prime} \mathrm{H} 1^{\prime}}$ exceeds $-4.9 \mathrm{~Hz}$. In this case, the apparent $\mathbf{J}$ coupling would fall outside the ranges covered by the corresponding Karplus equation. The same situation will apply to any NA fragments that have a comparable or higher anisotropy of the magnetic susceptibility at magnetic fields equal to or exceeding $22.3 \mathrm{~T}$. With the upcoming generation of NMR spectrometers operating at magnetic fields reaching up to $28 \mathrm{~T}$ and providing sensitivity and resolution suitable for structural investigations of large NA systems, the interpretation bias of the apparent ${ }^{1} \mathrm{~J}_{\mathrm{C1}^{\prime} \mathrm{H} 1^{\prime}}$ stemming from the fiRDC contribution will be even more pronounced. However, at the practical level, these large $\mathrm{fi}^{1} \mathrm{D}_{\mathrm{C} 1^{\prime} \mathrm{H} 1^{\prime}}$ contributions are unlikely to be overlooked because the measured apparent Js will fall out of the range defined by the established Karplus equation. In these cases, the apparent ${ }^{1} \mathrm{~J}_{\mathrm{C}^{\prime} \mathrm{H} 1^{\prime}}$ value that is uncorrected for the $\mathrm{fi}^{1} \mathrm{D}_{\mathrm{C} 1^{\prime} \mathrm{H} 1^{\prime}}$ will produce violations with other, magnetic field-independent NMR restraints, such as those from $\mathrm{H}^{\prime}{ }^{\prime}-\mathrm{H} 6 / 8$ NOEs. However, for NA fragments of moderate size (20-50 nt) measured at moderate-to-high magnetic fields (14-17 T), the $\mathrm{fi}^{1} \mathrm{D}_{\mathrm{C} 1^{\prime} \mathrm{H} 1^{\prime}}$ contribution might be easily unnoticed because the direct structural interpretation of the apparent ${ }^{1} \mathrm{~J}_{\mathrm{C}^{\prime}{ }^{\prime} \mathrm{H} 1^{\prime}}$ will still lie within the ranges indicated by loosely defined $\mathrm{H}^{\prime}-\mathrm{H} 6 / 8$ NOEs. A direct interpretation of the apparent ${ }^{1} \mathrm{~J}_{\mathrm{C} 1^{\prime} \mathrm{H} 1^{\prime}}$ (without correction for $\mathrm{fi}^{1} \mathrm{D}_{\mathrm{C}^{\prime} \mathrm{H}^{\prime}}$ ) will provide a correct assignment of the $\chi$ torsion angle, e.g., into the anti-periplanar region (Fig. 2); however, in quantitative terms, an under- or over-estimation of the $\chi$ for a single base by more than $20^{\circ}$ is expected to propagate through the NA helix via the van der Waals term describing stacking and base 

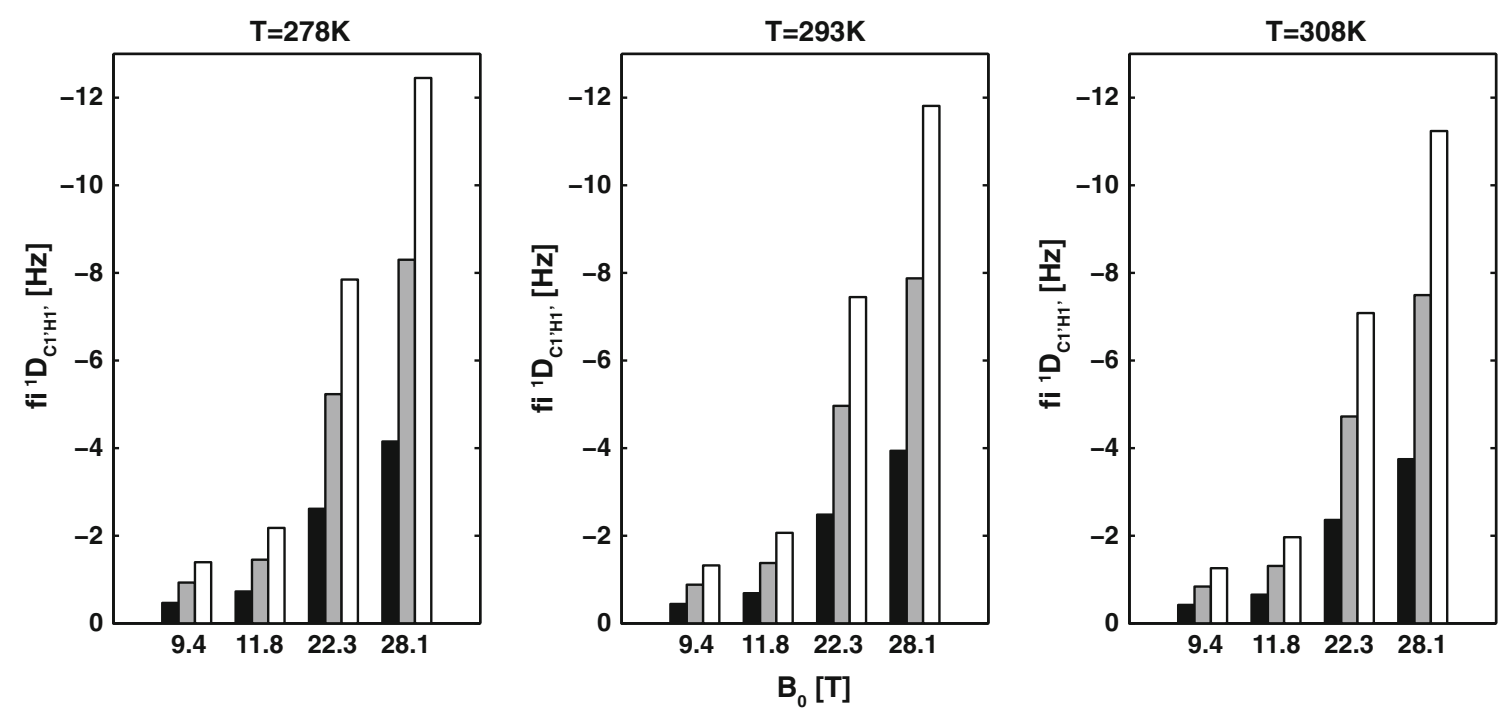

Fig. 1 Calculated $\mathrm{fi}^{1} \mathrm{D}_{\mathrm{Cl}^{\prime} \mathrm{H} 1^{\prime}}$ values for residue $\mathrm{G} 10$ in canonical B-DNA. Each $\mathrm{fi}^{1} \mathrm{D}_{\mathrm{C1}^{\prime} \mathrm{H} 1^{\prime}}$ value was computed at four magnetic field strengths $\mathrm{B}_{0}(9.4,11.8,22.3$, and $28.1 \mathrm{~T})$, three different temperatures

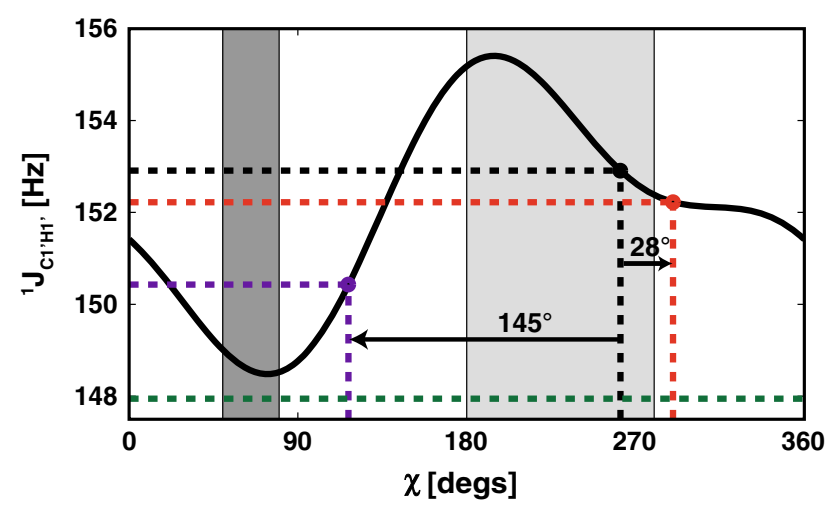

Fig. 2 The Karplus curve for ${ }^{1} \mathrm{~J}_{\mathrm{C1}^{\prime} \mathrm{H} 1^{\prime}}$ (parameterization according to Munzarova and Sklenar 2003). The black filled circle corresponds to the true ${ }^{1} \mathrm{~J}_{\mathrm{Cl}^{\prime} \mathrm{H} 1^{\prime}}$ coupling $(152.9 \mathrm{~Hz})$ expected for residue $\mathrm{G} 10$ $\left(\chi=262^{\circ}\right)$ in the $12 \mathrm{bp}$ canonical B-DNA. The red and purple filled circles indicate the apparent ${ }^{1} \mathrm{~J}_{\mathrm{Cl}^{\prime} \mathrm{H} 1^{\prime}}$ values that correspond to the sum of the true ${ }^{1} \mathrm{~J}_{\mathrm{Cl}^{\prime} \mathrm{H}^{\prime}}$ values and the dipolar contributions resulting from the DNA fragment self-alignment at $293 \mathrm{~K}$ and at magnetic field strengths of $11.8 \mathrm{~T}(-0.7 \mathrm{~Hz})$ and $22.3 \mathrm{~T}(-2.5 \mathrm{~Hz})$, respectively. The arrows indicate the errors in the interpretation of the apparent ${ }^{1} \mathrm{~J}_{\mathrm{C}^{\prime} \mathrm{H} 1^{\prime}}$ value due to dipolar contributions. For the $24 \mathrm{bp}$ fragment at $293 \mathrm{~K}$ and a magnetic field strength of $22.3 \mathrm{~T}$, the dipolar contribution reaches $\sim 5 \mathrm{~Hz}$; thus, the apparent ${ }^{1} \mathrm{~J}_{\mathrm{Cl}^{\prime} \mathrm{H} 1^{\prime}}$ value falls outside the ranges defined by the Karplus curve (green dashed line). The light grey area indicates the boundaries typical for the anti conformation of $\chi\left(180^{\circ}-280^{\circ}\right)$. The dark grey area marks the typical boundaries for the syn conformation of $\chi\left(50^{\circ}-80^{\circ}\right)$

separation and inter-base NOEs in the rMD, which is typically employed for NMR restraint-based structure determination.

For other structurally important ${ }^{1} \mathrm{~J}_{\mathrm{CH}} \mathrm{S}$, such as ${ }^{1} \mathrm{~J}_{\mathrm{C} 3^{\prime} \mathrm{H}^{\prime}}$ and ${ }^{1} \mathrm{~J}_{\mathrm{C}^{\prime} \mathrm{H}^{\prime}}$ that provide information about the
$\mathrm{T}(278,293$, and $308 \mathrm{~K})$ and three different fragment lengths (12, 24, and $36 \mathrm{bp}$ ). The $12 \mathrm{bp}$ fragment is indicated in black, the $24 \mathrm{bp}$ fragment in grey, and the $36 \mathrm{bp}$ fragment in white

conformation of the sugar ring or ${ }^{1} \mathrm{~J}_{\mathrm{H}^{\prime} \mathrm{C} 5^{\prime}}$ and ${ }^{1} \mathrm{~J}_{\mathrm{H} 5^{\prime \prime} \mathrm{C} 5^{\prime}}$, which are used for stereospecific assignment of the $\mathrm{H}^{\prime}$ and $\mathrm{H}^{\prime \prime}$ resonances, the situation is analogous to the ${ }^{1} \mathrm{~J}_{\mathrm{Cl}^{\prime} \mathrm{H}^{\prime}}$. In general, the absolute values of the corresponding fiRDCs increase with increasing magnetic field strength as well as with increasing nucleic acid fragment sizes (Supplementary Information-Tables S2 and S3). The interpretation of ${ }^{1} \mathrm{~J}_{\mathrm{C}^{\prime} \mathrm{H}^{\prime}}$ and ${ }^{1} \mathrm{~J}_{\mathrm{C}^{\prime} \mathrm{H}^{\prime}}$ is based on the observation that for $\mathrm{N}$-type sugars, the ${ }^{1} \mathrm{~J}_{\mathrm{C}^{\prime} \mathrm{H} 2^{\prime}}$ and the ${ }^{1} \mathrm{~J}_{\mathrm{C}^{\prime} \mathrm{H}^{\prime}}$ values are approximately $8 \mathrm{~Hz}$ higher and lower, respectively, than their values in S-type sugars (Ippel et al. 1996). For ${ }^{1} \mathrm{~J}_{\mathrm{C}^{\prime} \mathrm{H} 2^{\prime}}$ and ${ }^{1} \mathrm{~J}_{\mathrm{C}^{\prime} \mathrm{H}^{\prime}}$ in both N-type and S-type sugars, the corresponding fiRDCs are significant, and they have comparable magnitudes and signs (Supplementary InformationTables S2 and S3). Consequently, the fiRDCs for those Js do not change their relative differences and do not affect their structural interpretation. The situation with the $\mathrm{fi}^{1-}$ $\mathrm{D}_{\mathrm{C}^{\prime} \mathrm{H}^{\prime} / \mathrm{H}^{\prime \prime}}$ demonstrates that fiRDC might even, in certain cases, facilitate the NA structure determination process. The ${ }^{1} \mathrm{~J}_{\mathrm{H}^{\prime} \mathrm{C} 5^{\prime}}$ and ${ }^{1} \mathrm{~J}_{\mathrm{H} 5^{\prime \prime} \mathrm{C} 5^{\prime}}$ values are being used for the stereospecific assignment of $\mathrm{H}^{\prime}$ and $\mathrm{H} 5^{\prime \prime}$. The assignment is based on fact that ${ }^{1} \mathrm{~J}_{\mathrm{H}^{\prime} \mathrm{C} 5^{\prime}}$ is generally larger than ${ }^{1} \mathrm{~J}_{\mathrm{H}^{\prime \prime} \mathrm{C5}^{\prime}}$ (Ippel et al. 1996). The presence of the $\mathrm{fi}^{1} \mathrm{D}_{\mathrm{C}^{\prime} \mathrm{H}^{\prime}}$ and $\mathrm{fi}^{1-}$ $\mathrm{D}_{\mathrm{C5}^{\prime} \mathrm{H} 5^{\prime \prime}}$ contributions makes the difference between the ${ }^{1} \mathrm{~J}_{\mathrm{H}^{\prime} \mathrm{C}^{\prime}}$ and ${ }^{1} \mathrm{~J}_{\mathrm{H} 5^{\prime \prime} \mathrm{C} 5^{\prime}}$ values even more pronounced because the absolute magnitudes of $\mathrm{fi}^{1} \mathrm{D}_{\mathrm{H}^{\prime} \mathrm{C5}^{\prime}}$ and $\mathrm{fi}^{1} \mathrm{D}_{\mathrm{H} 5^{\prime \prime} \mathrm{C} 5^{\prime}}$ are comparable, whereas their signs differ (Supplementary Information-Tables S2 and S3). Taken together, these results show the following: For $\mathrm{fi}^{1} \mathrm{D}_{\mathrm{Cl}^{\prime} \mathrm{H1}^{\prime}}$, disregarding the dipolar contribution is always connected with interpretational bias. In contrast, the fiRDC contributions to ${ }^{1} \mathrm{~J}_{\mathrm{C}^{\prime}} \mathrm{H}^{\prime}$ and ${ }^{1} \mathrm{~J}_{\mathrm{C} 2^{\prime} \mathrm{H} 2^{\prime}}$ as well as those to ${ }^{1} \mathrm{~J}_{\mathrm{H}^{\prime} \mathrm{C}^{\prime}}$ and ${ }^{1} \mathrm{~J}_{\mathrm{H} 5^{\prime \prime} \mathrm{C} 5^{\prime}}$ is not 
expected to impair the corresponding apparent ${ }^{1} \mathrm{~J}_{\mathrm{C}-\mathrm{H}} \mathrm{S}$ interpretation.

\section{Effect of self-alignment on the interpretation of ${ }^{3} J_{\mathrm{HH}}$}

A second group of $\mathrm{J}$ couplings that are notably affected by fiRDC contributions are the three-bond proton-proton scalar couplings $\left({ }^{3} \mathrm{~J}_{\mathrm{HH}}\right)$. Although the inter-proton distance between scalar coupled protons over three bonds is considerably longer than that of the one-bond $\mathrm{C}-\mathrm{H}$, the fiRDC contribution to ${ }^{3} \mathrm{~J}_{\mathrm{HH}}$ arises due to the large value of the product of the proton gyromagnetic constants (see Eq. 5). Nonetheless, compared to $\mathrm{fi}^{1} \mathrm{D}_{\mathrm{CH}}$, the $\mathrm{fi}^{3} \mathrm{D}_{\mathrm{HH}}$ values are notably smaller, ranging from $|0.1|$ to $|3| \mathrm{Hz}$ for fragments between 12 and $36 \mathrm{bp}$ and magnetic fields strength of 9.4-22.3 T (Supplementary Information-Tables S2 and $\mathrm{S} 3$ ). Among the ${ }^{3} \mathrm{~J}_{\mathrm{HH}} \mathrm{S}$ commonly used for NA structure determination, two ${ }^{3} \mathrm{~J}_{\mathrm{HH}} \mathrm{S}$ are particularly useful in the determination of the conformation of the sugar ring, namely ${ }^{3} \mathrm{~J}_{\mathrm{H}^{\prime} \mathrm{H}^{\prime}}$ and ${ }^{3} \mathrm{~J}_{\mathrm{H}^{\prime}{ }^{\prime} 4^{\prime}}$. Our calculations indicate that for small double helical NA fragments $(\sim 12 \mathrm{bp})$ investigated at low magnetic field strengths $(<12 \mathrm{~T})$, neither $\mathrm{fi}^{3-}$ $\mathrm{D}_{\mathrm{H} 1^{\prime} \mathrm{H} 2^{\prime}}$ nor $\mathrm{fi}^{3} \mathrm{D}_{\mathrm{H}^{\prime} \mathrm{H}^{\prime}}(\sim 0.3 \mathrm{~Hz})$ biases the qualitative interpretation of the apparent ${ }^{3} \mathrm{~J}_{\mathrm{H}^{\prime} \mathrm{H}^{\prime}}$ and ${ }^{3} \mathrm{~J}_{\mathrm{H} 3^{\prime} \mathrm{H} 4^{\prime}}$ values in terms of the sugar pucker conformation (Figs. 4, 5). However, the calculations show that the $\mathrm{fi}^{3} \mathrm{D}_{\mathrm{H} 1^{\prime} \mathrm{H} 2^{\prime}}$ contribution reaches $\sim 2 \mathrm{~Hz}$ (Fig. 3a, Supplementary Information-Table S2) for the $24 \mathrm{bp}$ A-RNA fragment at $22.3 \mathrm{~T}$. Analysis of the effect of the $\mathrm{fi}^{3} \mathrm{D}_{\mathrm{H} 1^{\prime} \mathrm{H} 2^{\prime}}$ value on interpretation of the apparent ${ }^{3} \mathrm{~J}_{\mathrm{H} 1^{\prime} \mathrm{H} 2^{\prime}}$ shows that such fiRDC will produce a $27^{\circ}$ error in the torsion angle $\phi_{\mathrm{H}^{\prime} \mathrm{H} 2^{\prime}}$ (Fig. 4). At

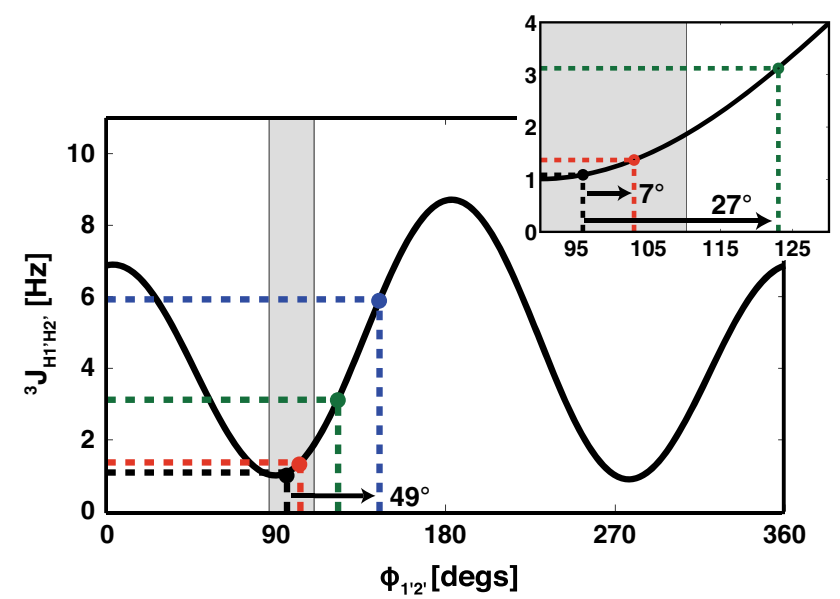

Fig. 4 The Karplus curve for ${ }^{3} \mathrm{~J}_{\mathrm{H}^{\prime} \mathrm{H}^{\prime}}$ (parameterization according to Roberts Munzarova and Sklenar 2003). The black filled circle corresponds to the true ${ }^{3} \mathrm{~J}_{\mathrm{H}^{\prime}-\mathrm{H} 2^{\prime}}$ coupling $(1.1 \mathrm{~Hz})$ expected for residue $\mathrm{C} 3$ (torsion angle $\phi_{1^{\prime} 2^{\prime}}=96^{\circ}$ ) in the 12 bp canonical A-RNA. The red, green, and blue filled circles indicate the apparent ${ }^{3} \mathrm{~J}_{\mathrm{H} 1^{\prime} \mathrm{H} 2^{\prime}}$ values that correspond to the sum of true ${ }^{3} \mathrm{~J}_{\mathrm{H} 1^{\prime} \mathrm{H} 2^{\prime}}$ values and the dipolar contributions resulting from the self-alignment of the 12, 24, and $36 \mathrm{bp}$ RNA fragments at $293 \mathrm{~K}$ and at a magnetic field strength of $11.8 \mathrm{~T}(0.3 \mathrm{~Hz}), 22.8 \mathrm{~T}(2 \mathrm{~Hz})$ and $28.1 \mathrm{~T}(4 \mathrm{~Hz})$, respectively. The arrows in the inset indicate the errors in the interpretation of the apparent ${ }^{3} \mathrm{~J}_{\mathrm{H}^{\prime} \mathrm{H} 2^{\prime}}$ value due to dipolar contributions. The light grey area indicates the $\phi_{1^{\prime} 2^{\prime}}$ torsion angle boundaries typical for the $\mathrm{C}^{\prime}$ endo conformation $\left(86^{\circ}-110^{\circ}\right)$ for $\mathrm{P}^{\mathrm{N}}=<0^{\circ}, 36^{\circ}>$ and $\varphi_{m}=$ $<35^{\circ}, 42^{\circ}>$ (Roberts 1993)

a field strength of $28 . \mathrm{T}$, the error in the torsion angle $\phi_{\mathrm{H}^{\prime}{ }^{\prime} 2^{\prime}}$ due to an fiRDC contribution reaching $\sim 3.2 \mathrm{~Hz}$ (Supplementary Information-Table S2) for 36 bp A-RNA will reach almost $50^{\circ}$ (Fig. 4).
Fig. 3 Calculated $\mathrm{fi}^{3} \mathrm{D}_{\mathrm{H}^{\prime}-\mathrm{H} 2^{\prime}}$ for residues $\mathrm{C} 3$ (a) and $\mathrm{G} 10$ (b) in canonical A-RNA and B-DNA, respectively. The dipolar coupling values are computed at $293 \mathrm{~K}$, at four magnetic field strengths $\mathrm{B}_{0}(9.4$, 11.8, 22.3, and 28.1 T), and three different NA fragment lengths $(12,24$, and $36 \mathrm{bp})$. The $12 \mathrm{bp}$ fragment is indicated in black, the $24 \mathrm{bp}$ fragment in grey, and the $36 \mathrm{bp}$ fragment in white
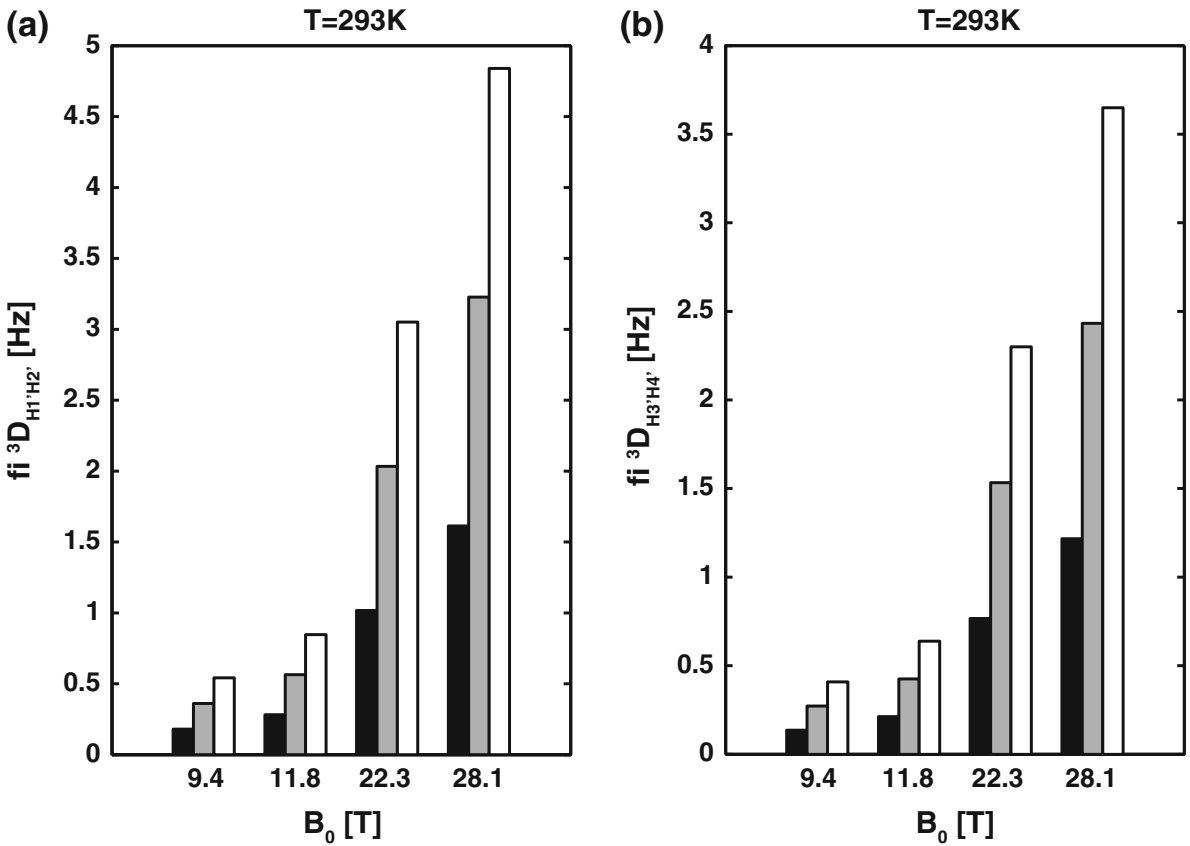
For the apparent ${ }^{3} \mathrm{~J}_{\mathrm{H}^{\prime} \mathrm{H} 4^{\prime}}$, our calculation indicates that the corresponding $\mathrm{fi}^{3} \mathrm{D}_{\mathrm{H} 3^{\prime} \mathrm{H} 4^{\prime}}$ reaches $\sim 1.5 \mathrm{~Hz}$ (Fig. 3b, Supplementary Information-Table S3) for the $24 \mathrm{bp}$ B-DNA fragment at $22.3 \mathrm{~T}$. Analysis of the effect of the $\mathrm{fi}^{3} \mathrm{D}_{\mathrm{H} 3^{\prime} \mathrm{H} 4^{\prime}}$ on the interpretation of the apparent ${ }^{3} \mathrm{~J}_{\mathrm{H} 3^{\prime} \mathrm{H} 4^{\prime}}$ shows that such fiRDC will produce a $16^{\circ}$ error in the pseudo-torsion angle $\phi_{\mathrm{H}^{\prime}{ }^{\prime} 4^{\prime}}$ (Fig. 5). The error increases with increases in the size of the NA fragment ( $36 \mathrm{bp}$ ) and increases in the strength of the magnetic field (28.1 T) up to $32^{\circ}$ (Fig. 5).

\section{${ }^{2 / 3 / 4} \mathrm{~J}_{\mathrm{CH}}$ and ${ }^{2 / 3 / 4} \mathrm{~J}_{\mathrm{HP}}$ fiRDC}

At currently used magnetic field strengths, the fiRDC contributions to the other commonly used Js in the NMR structure determination of NAs, namely 2- to 4-bond $\mathrm{J}_{\mathrm{CH}} \mathrm{S}$ and $\mathrm{J}_{\mathrm{HP}} \mathrm{S}$, are generally below the experimental error and well-within the error bounds used for the $\mathrm{J}$ interpretation of nucleic acid structure (Supplementary InformationTables S2 and S3). However, at the magnetic fields corresponding to the current state-of-the-art $1 \mathrm{GHz}$ spectrometers and the upcoming generation of $1.2 \mathrm{GHz}$ spectrometers, the fiRDC contribution to a number of these

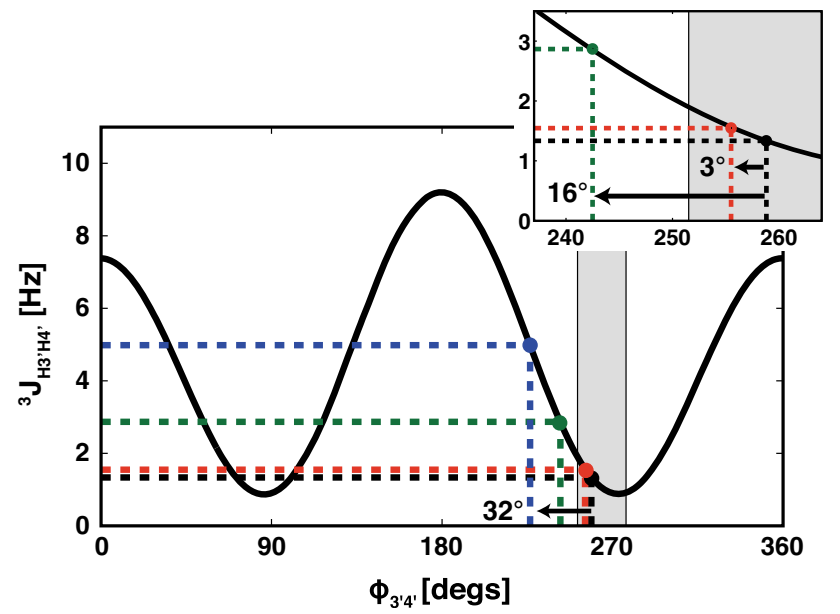

Fig. 5 The Karplus curve for ${ }^{3} \mathrm{~J}_{\mathrm{H}^{\prime} \mathrm{H}^{\prime}}$ (parameterization according to Roberts (Munzarova and Sklenar 2003)). The black filled circle corresponds to the true ${ }^{3} \mathrm{~J}_{\mathrm{H}^{\prime} \mathrm{H} 4^{\prime}}$ coupling $(1.3 \mathrm{~Hz}$ ) expected for residue G10 (torsion angle $\phi_{3^{\prime} 4^{\prime}}=258.8^{\circ}$ ) in the 12 bp canonical B-DNA. The red, green, and blue filled circles indicate the apparent ${ }^{3} \mathrm{~J}_{\mathrm{H}^{\prime} \mathrm{H}^{\prime}}$ values that correspond to the sum of the true ${ }^{3} \mathrm{~J}_{\mathrm{H} 3^{\prime} \mathrm{H}^{\prime}}$ values and the dipolar contributions resulting from the self-alignment of the 12, 24, and $36 \mathrm{bp}$ DNA fragments at $293 \mathrm{~K}$ and at magnetic field strengths of $11.8 \mathrm{~T}(0.2 \mathrm{~Hz}), 22.8 \mathrm{~T}(1.5 \mathrm{~Hz})$ and $28.1 \mathrm{~T}(3.6 \mathrm{~Hz})$, respectively. The arrows in the inset indicate the errors in the interpretation of the apparent ${ }^{3} \mathrm{~J}_{\mathrm{H} 1^{\prime}-\mathrm{H} 2^{\prime}}$ due to the dipolar contributions. The light grey area indicates the typical $\phi_{3^{\prime} 4^{\prime}}$ torsion angle boundaries for the $\mathrm{C} 2^{\prime}$-endo conformation $\left(86^{\circ}-110^{\circ}\right)$ for $\mathrm{P}^{\mathrm{N}}=<0^{\circ}, 36^{\circ}>$ and $\left.\varphi_{m}=<35^{\circ}, 42^{\circ}\right\rangle$ (Roberts 1993) structurally important Js become notable and should be taken into consideration during Js structural interpretations (Supplementary Information-Tables S2 and S3). In situations when significant errors are suspected, the pure $\mathrm{J}$ value should be determined from measurements at two or more magnetic field strengths (Bryce et al. 2004).

$$
\begin{aligned}
& \left\{\left({ }^{n} J_{I S}+{ }^{n} D_{I S}\right)^{\text {high }}-\left({ }^{n} J_{I S}+{ }^{n} D_{I S}\right)^{l o w}\right\}\left[\frac{\left(B_{0}^{\text {high }}\right)}{\left(B_{0}^{\text {high }}\right)^{2}-\left(B_{0}^{\text {low }}\right)^{2}}\right] \\
& =-\left[\frac{\mu_{0}\left(B_{0}\right)^{2} \Delta \chi S \gamma_{I} \gamma_{S} h}{240 \pi^{3} k T r_{I S}^{3}}\right]\left[\left(3 \cos ^{2} \theta-1\right)+\frac{3}{2} R \sin ^{2} \theta \cos 2 \phi\right]
\end{aligned}
$$

where $\mathrm{B}^{\text {high }}$ and $\mathrm{B}^{\text {low }}$ corresponds to high and low magnetic field strengths, respectively. $(\mathrm{J}+\mathrm{D})^{\text {high }}$ and $(\mathrm{J}+\mathrm{D})^{\text {low }}$ correspond to the apparent $\mathrm{J}$ extracted from the measurements at low and high magnetic field strengths, respectively. Such measurements, however, impose requirements on the available instrumentation and experimental time. On the other hand, at ultra-high magnetic fields, the extracted fiRDC values are expected to become an important source of long-range structural restraints under non-invasive conditions. Avoiding the use of alignment media is particularly important for DNA, which displays notable sensitivity towards non-specific physical-chemical factors, such as ion strength, ion type, molecular crowding, water activity and/or the presence of small osmolytes (Fiala et al. 2011; Hansel et al. 2011).

In the process of $\mathrm{J}$ coupling interpretation the errors from fiRDCs, which are the subject of the present study, will add to the other known errors such as those due to neglect of $\mathrm{J}$ averaging by internal motion and those due to passive spin-relaxation, referred to as spin-flip(s) (Harbison 1993; Bruschweiler and Case 1994; Vogeli et al. 2008). The spin-flip phenomenon comes for the interference between J-coupling and cross-relaxation and its primary effect is reduction in apparent $J$. As the effect of spin flip is indirectly proportional to $\mathrm{T}_{1}$, the respective error is most significant for small NA fragments (studied at low magnetic fields) and decreases rapidly with the molecular size (particularly when studied at high magnetic fields). For example, the error in ${ }^{3} \mathrm{~J}_{\mathrm{HH}}$ coupling due to spin-flip reaches up to $1 \mathrm{~Hz}$ for $12-14 \mathrm{bp}$ NA fragment while the corresponding error will be smaller than $0.1 \mathrm{~Hz}$ for $36 \mathrm{bp}$ NA fragment (Harbison 1993). Similarly to the error due to spin flip, the averaging of $\mathbf{J}$ by internal motion leads to reduction in apparent $\mathrm{J}$. For structured parts of NA, the errors due to the neglect of motional $\mathrm{J}$ averaging are expected to be smaller than $1 \mathrm{~Hz}$ (Bruschweiler and Case 1994; Trantirek et al. 2002; Vokacova et al. 2009). Altogether, the neglect of fiRDC contribution appears to be one 
of the most significant sources of bias in quantitative interpretation of $\mathrm{J}$ couplings, especially for medium to larger size nucleotides studied in high magnetic fields.

\section{Conclusion}

The fiRDCs can serve as both an important source of information on the structure and dynamics as well as, if not properly accounted for, a source of structural artifacts/bias in the solution NMR spectroscopy of nucleic acids. Although the usefulness of the fiRDCs for the structural characterization of nucleic acids and their complexes was demonstrated by number of studies (Al-Hashimi 2013; Al-Hashimi et al. 2001b; Zhang and Al-Hashimi 2008), the contributions from fiRDCs to apparent J couplings are among the current most overlooked sources of artifacts in the structure determination of nucleic acids. With recent advances in NMR instrumentation as well as in the automation of the nucleic acid structure determination process, NMR spectroscopy is becoming accessible to a growing community of non-expert users employing pre-programmed "black-box" routines for the interpretation of acquired primary NMR data. The corrections for the fiRDCs are not routinely implemented in the current generation of programs for automated nucleic acid structure determination; thus, an unquestioning use of these programs might adversely affect the quality of NA structures derived from solution NMR data. The situation is expected to worsen in the future with the upcoming generations of NMR spectrometers operating at magnetic fields of up to $28 \mathrm{~T}$, where the fiRDC contributions to apparent J couplings will in many cases become comparable to or even exceed the modulation of the $\mathrm{J}$ couplings due to the local conformation. At the currently commonly available magnetic fields (11-17 T), disregarding the fiRDC contributions when interpreting $\mathrm{J}$ couplings could in principle be tolerated for the production of low-resolution structural models based on semi-quantitative NMR data; however, properly accounting for fiRDCs appears to be essential for the production of precise and accurate nucleic acid structures. Moreover, accounting for fiRDC contributions is particularly important in applications involving empirical (re)-parameterizations of Karplus equations. Studies that correlate experimental J couplings with the $\mathrm{J}$ couplings from quantum chemical calculations, especially studies aiming at benchmarking the calculation methods, must pay particular attention to the fiRDC-induced contamination of J.

Acknowledgments This work was supported by the Czech Science Foundation (13-28310S, 13-27676S, 16-10504S), by the Grant M200551205 from Academy of Sciences of the Czech Republic, R\&D development grant from INSTRUCT and the Project "CEITEC" (CZ.105/1.100/02.0068). LT was supported by a career development grant from the European Organization for Molecular
Biology (IG2535) and an ECOPOD grant from the Marie-Curie Reintegration program.

Open Access This article is distributed under the terms of the Creative Commons Attribution 4.0 International License (http://creative commons.org/licenses/by/4.0/), which permits unrestricted use, distribution, and reproduction in any medium, provided you give appropriate credit to the original author(s) and the source, provide a link to the Creative Commons license, and indicate if changes were made.

\section{References}

Al-Hashimi HM (2013) NMR studies of nucleic acid dynamics. J Magn Reson 237:191-204

Al-Hashimi HM, Gorin A, Majumdar A, Patel DJ (2001a) Alignment of the HTLV-I Rex peptide bound to its target RNA aptamer from magnetic field-induced residual dipolar couplings and intermolecular hydrogen bonds. J Am Chem Soc 123:3179-3180

Al-Hashimi HM, Majumdar A, Gorin A, Kettani A, Skripkin E, Patel DJ (2001b) Field- and phage-induced dipolar couplings in a homodimeric DNA quadruplex, relative orientation of $\mathrm{G}$ center $\operatorname{dot}(\mathrm{C}-\mathrm{A})$ triad and G-tetrad motifs and direct determination of C2 symmetry axis orientation. J Am Chem Soc 123:633-640

Al-Hashimi HM, Tolman JR, Majumdar A, Gorin A, Patel DJ (2001c) Determining stoichiometry in homomultimeric nucleic acid complexes using magnetic field induced residual dipolar couplings. J Am Chem Soc 123:5806-5807

Alkorta I, Elguero J, Denisov GS (2008) A review with comprehensive data on experimental indirect scalar NMR spin-spin coupling constants across hydrogen bonds. Magn Reson Chem 46:599-624

Bax A, Tjandra N (1997) High-resolution heteronuclear NMR of human ubiquitin in an aqueous liquid crystalline medium. J Biomol NMR 10:289-292

Bax A, Vuister GW, Grzesiek S, Delaglio F, Wang AC, Tschudin R, Zhu G (1994) Measurement of homonuclear and heteronuclear J-couplings from quantitative J-correlation. Method Enzymol 239:79-105

Becke AD (1993) Density-functional thermochemistry. III. The role of exact exchange. J Chem Phys 98:5648-5652

Brandes R, Kearns DR (1986) Magnetic ordering of DNA liquid crystals. Biochemistry 25:5890-5895

Bruschweiler R, Case DA (1994) Adding harmonic motion to the Karplus relation for Spin-Spin coupling. J Am Chem Soc 116:11199-11200

Bryce DL, Boisbouvier J, Bax A (2004) Experimental and theoretical determination of nucleic acid magnetic susceptibility: importance for the study of dynamics by field-induced residual dipolar couplings. J Am Chem Soc 126:10820-10821

Case DA et al (2008) AMBER 10. University of California, San Francisco

Cheeseman JR, Trucks GW, Keith TA, Frisch MJ (1996) A comparison of models for calculating nuclear magnetic resonance shielding tensors. J Chem Phys 104:5497-5509

Clore GM, Starich MR, Gronenborn AM (1998) Measurement of residual dipolar couplings of macromolecules aligned in the nematic phase of a colloidal suspension of rod-shaped viruses. J Am Chem Soc 120:10571-10572

Clowney L, Jain SC, Srinivasan AR, Westbrook J, Olson WK, Berman HM (1996) Geometric parameters in nucleic acids: nitrogenous bases. J Am Chem Soc 118:509-518

Ditchfield R, Hehre WJ, Pople JA (1971) Self-consistent molecularorbital methods. IX. An extended gaussian-type basis for 
molecular-orbital studies of organic molecules. J Chem Phys 54:724-728

Fiala R, Špačková N, Foldynová-Trantírková S, Šponer J, Sklenář V, Trantírek L (2011) NMR cross-correlated relaxation rates reveal ion coordination sites in DNA. J Am Chem Soc 133:13790 13793

Fonville JM et al (2012) Chemical shifts in nucleic acids studied by density functional theory calculations and comparison with experiment. Chem Eur J 18:12372-12387

Frisch MJ et al (2009) Gaussian 09 Revision A.02. Gaussian, Inc, Wallingford

Griesinger C, Sorensen OW, Ernst RR (1985) Two-dimensional correlation of connected NMR transitions. J Am Chem Soc 107:6394-6396

Hansel R, Lohr F, Foldynova-Trantirkova S, Bamberg E, Trantirek L, Dotsch V (2011) The parallel G-quadruplex structure of vertebrate telomeric repeat sequences is not the preferred folding topology under physiological conditions. Nucleic Acids Res 39:5768-5775

Harbison GS (1993) Interference between J-couplings and crossrelaxation in solution NMR spectroscopy: consequences for macromolecular strcuture determination. J Am Chem Soc 115:3026-3027

Iizuka E (1978) Orientation of liquid-crystals of polyribonucleotide complexes in a static magnetic-field. Polym J 10:235-237

Iizuka E, Kondo Y (1979) Magnetic-field orientation of the liquidcrystals of polyribonucleotide complexes Mol Cryst Liq Cryst 51:285-293

Iizuka E, Yang JT (1977) Formation of liquid-crystals of polyribonculeotide complexes. Abstr Pap Am Chem Soc 174:93

Ippel JH et al (1996) Heteronuclear scalar couplings in the bases and sugar rings of nucleic acids: their determination and application in assignment and conformational analysis. Magn Reson Chem 34:S156-S176

Kontaxis G, Clore GM, Bax A (2000) Evaluation of cross-correlation effects and measurement of one-bond couplings in proteins with short transverse relaxation times. J Magn Reson 143:184-196

Kung HC, Wang KY, Goljer I, Bolton PH (1995) Magnetic alignment of duplex and quadruplex DNAs. J Magn Reson 109:323-325

Lu XJ (2003) 3DNA: a software package for the analysis, rebuilding and visualization of three-dimensional nucleic acid structures. Nucleic Acids Res 31:5108-5121

Meissner A, Duus J, Sørensen O (1997a) Integration of spin-stateselective excitation into 2D NMR correlation experiments with heteronuclear $\mathrm{ZQ} / 2 \mathrm{Q} \pi$ rotations for $1 \mathrm{JXH}$. J Biomol NMR 10:89-94

Meissner A, Jø Duus, Sørensen OW (1997b) Spin-state-selective excitation. Application for E.COSY-type measurement of JHH coupling constants. J Magn Reson 128:92-97

Miertus S, Tomasi J (1982) Approximate evaluations of the electrostatic free energy and internal energy changes in solution processes. Chem Phys 65:239-245

Miertuš S, Scrocco E, Tomasi J (1981) Electrostatic interaction of a solute with a continuum. A direct utilizaion of $\mathrm{AB}$ initio molecular potentials for the prevision of solvent effects. Chem Phys 55:117-129

Munzarova ML, Sklenar V (2003) DFT analysis of NMR scalar interactions across the glycosidic bond in DNA. J Am Chem Soc 125:3649-3658

Ottiger M, Delaglio F, Bax A (1998) Measurement of J and dipolar douplings from simplified two-dimensional NMR spectra. J Magn Reson 131:373-378

Rill RL (1986) Liquid crystalline phases in concentrated aqueous solutions of Na+ DNA. PNAS 83:342-346

Rill RL, Hilliard PR, Levy GC (1983) Spontaneous ordering of DNA. Effects of intermolecular interactions on DNA motional dynamics monitored by $13 \mathrm{C}$ and $31 \mathrm{P}$ nuclear magnetic resonance spectroscopy. J Biol Chem 258:250-256

Roberts GC (1993) NMR of macromolecules: a practical approach. Oxford University Press, UK

Robinson C (1961) Liquid-crystalline structures in polypeptide solutions. Tetrahedron 13:219-234

Rückert M, Otting G (2000) Alignment of biological macromolecules in novel nonionic liquid crystalline media for NMR experiments. J Am Chem Soc 122:7793-7797

Sass H-J, Musco G, Stahl S, Wingfield P, Grzesiek S (2000) Solution NMR of proteins within polyacrylamide gels: diffusional properties and residual alignment by mechanical stress or embedding of oriented purple membranes. J Biomol NMR 18:303-309

Senechal E, Maret G, Dransfeld K (1980) Long-range order of nucleic-acids in aqueous-solutions. Int $\mathrm{J}$ Biol Macromol 2: 256-262

Su X-C, McAndrew K, Huber T, Otting G (2008) Lanthanide-binding peptides for NMR measurements of residual dipolar couplings and paramagnetic effects from multiple angles. J Am Chem Soc 130:1681-1687

Sychrovský V, Šponer J, Trantírek L, Schneider B (2006) Indirect NMR spin-spin coupling constants $3 \mathrm{~J}(\mathrm{P}, \mathrm{C})$ and $2 \mathrm{~J}(\mathrm{P}, \mathrm{H})$ across the $\mathrm{P}-\mathrm{O} \cdots \mathrm{H}-\mathrm{C}$ link can be used for structure determination of nucleic acids. J Am Chem Soc 128:6823-6828

Tjandra N, Bax A (1997) Direct measurement of distances and angles in biomolecules by NMR in a dilute liquid crystalline medium. Science 278:1111-1114

Tjandra N, Grzesiek S, Bax A (1996) Magnetic field dependence of nitrogen-proton $\mathrm{J}$ splittings in $\mathrm{N}$-15-enriched human ubiquitin resulting from relaxation interference and residual dipolar coupling. J Am Chem Soc 118:6264-6272

Trantirek L, Stefl R, Masse JE, Feigon J, Sklenar V (2002) Determination of the glycosidic torsion angles in uniformly C-13-labeled nucleic acids from vicinal coupling constants (3) J(C2/4-H1') and (3)J(C6/8-H1'). J Biomol NMR 23:1-12

Trohalaki S, Brian AA, Frisch HL, Lerman LS (1984) Scaling of the equilibrium sedimentation distribution in dense DNA solutions. Biophys J 45:777-782

Tycko R, Blanco FJ, Ishii Y (2000) Alignment of biopolymers in strained gels: a new way to create detectable dipole-dipole couplings in high-resolution biomolecular NMR. J Am Chem Soc 122:9340-9341

van Buuren BN, Schleucher J, Wittmann V, Griesinger C, Schwalbe $\mathrm{H}$, Wijmenga SS (2004) NMR spectroscopic determination of the solution structure of a branched nucleic acid from residual dipolar couplings by using isotopically labeled nucleotides. Angew Chem Int Ed Engl 43:187-192

Vogeli B, Yao L, Bax A (2008) Protein backbone motions viewed by intraresidue and sequential HN-Halpha residual dipolar couplings. J Biomol NMR 41:17-28

Vokacova Z, Bickelhaupt FM, Sponer J, Sychrovsky V (2009) Structural interpretation of $\mathbf{J}$ coupling constants in guanosine and deoxyguanosine: modeling the effects of sugar pucker, backbone conformation, and base pairing. J Phys Chem A 113:8379-8386

Wang AC, Bax A (1996) Determination of the backbone dihedral angles phi in human ubiquitin from reparametrized empirical Karplus equations. J Am Chem Soc 118:2483-2494

Wijmenga SS, van Buuren BNM (1998) The use of NMR methods for conformational studies of nucleic acids. Prog Nucl Magn Reson Spectrosc 32:287-387

Wöhnert J, Franz KJ, Nitz M, Imperiali B, Schwalbe H (2003) Protein alignment by a coexpressed lanthanide-binding tag for the measurement of residual dipolar couplings. J Am Chem Soc 125:13338-13339 
Wollinski K, Hinton JF, Pulay P (1990) Efficient implementation of the gauge-independent atomic orbital method for NMR chemical-shift calculations. J Am Chem Soc 112:8251-8260

Yao L, Ying J, Bax A (2009) Improved accuracy of 15 N-1H scalar and residual dipolar couplings from gradient-enhanced IPAPHSQC experiments on protonated proteins. J Biomol NMR 43:161-170

Zhang Q, Al-Hashimi HM (2008) Extending the NMR spatial resolution limit for RNA by motional couplings. Nat Methods 5:243-245

Zhang Q, Throolin R, Pitt SW, Serganov A, Al-Hashimi HM (2003) Probing motions between equivalent RNA domains using magnetic field induced residual dipolar couplings: accounting for correlations between motions and alignment. J Am Chem Soc 125:10530-10531

Zhou HJ, Vermeulen A, Jucker FM, Pardi A (1999) Incorporating residual dipolar couplings into the NMR solution structure determination of nucleic acids. Biopolymers 52:168-180

Zweckstetter M, Bax A (2001) Characterization of molecular alignment in aqueous suspensions of Pf1 bacteriophage. J Biomol NMR 20:365-377 